\title{
Research on the Incentives of Knowledge Employee from the Perspective of Management Psychology
}

\author{
Luqi Wang \\ School of Business Administration, China University of Petroleum-Beijing, Beijing, 102200, China
}

Keywords: Knowledge employee, Incentive system, Management psychology

\begin{abstract}
With the development of knowledge economy, knowledge workers have become the most important human resources of modern enterprises. If the enterprise wants to achieve greater development and progress, it is necessary to make the utmost effort to mobilize the enthusiasm of the knowledge staff. This paper analyzes the basic characteristics of the knowledge employee, and builds the incentive system of knowledge workers based on the management psychology, including rapid growth opportunities, constructing competitive salary system, implementing reasonable work authorization and establishing harmonious culture atmosphere to provide some references for the relevant researchers.

The knowledge employee is an important component of the strategic resources of the enterprise, and it is the foundation for the enterprise to survive and develop. At present, many enterprises lack some positive and effective incentive mechanisms, which leads to significant loss of talents in enterprises, so enterprises also lose core competitiveness. It is obvious that incentive mechanism is a very important means in the management of the growth of knowledge-based employees. The active and effective incentive mechanism can tap into the potential of the employees and give full play to their intrinsic potential to promote the long-term development of the enterprise. As it is known to all, science and technology are important tools for the development of production, and talent is the main body of the creation of advanced technology. Under the background of increasingly fierce market competition, it is necessary to continuously introduce new and high technology talents, train high and new technology talents, and do the best to improve employees' enthusiasm and initiative to continuously improve their market competitiveness.
\end{abstract}

\section{Concept and Characteristics of Knowledge Employee}

\subsection{Concept}

The concept of knowledge employees was first proposed by Drucker, the master of the management of the United States. He described knowledge workers as "those who master and use symbols and concepts, use knowledge or information." Canadian knowledge management scientist Francis Harry defined that "knowledge workers are those who bring additional value to their products through their own creativity, analysis, judgement, synthesis and design". The author thinks that knowledge workers are those who have a certain depth in thought, has the ability of knowledge application, expansion and innovation, bring the rapid increment of knowledge capital and material capital as the occupation mental workers, including the enterprise management personnel, engineering and technical personnel, research personnel and senior business personnel.

\subsection{Characteristics}

The characteristics of knowledge employee are shown in Figure 1.

Compared with non-knowledge employees, knowledge employees have a lot of particularity in their personal qualities, values and personal needs. Knowledge employees have received professional education system. They have abundant knowledge and skills, and their learning ability, a strong thirst for knowledge of the outside world, drives them to increase their knowledge, expand their horizons, to continuously enhance the content of human capital, create value for the enterprise. 
Knowledge workers are more closely related to their own career development, the realization of their value, and the affirmation and recognition of other employees and superiors in the organization. They often want to engage in more challenging tasks, achieve personal value, and hope that their work can be more diversified, play their role as much as possible, and achieve self-value by completing challenging tasks.

Most of the knowledge-based employees are engaged in creative work. They rely on their professional knowledge and brains to carry out creative thinking. Therefore, knowledge workers are more inclined to have a relaxed and highly autonomous working environment, and emphasize self-guidance and self-management in their work. Therefore, talent competition has become the focus of competition among different countries and organizations. Knowledge employees often have higher liquidity to better realize their value and pursue suitable environment for their development.

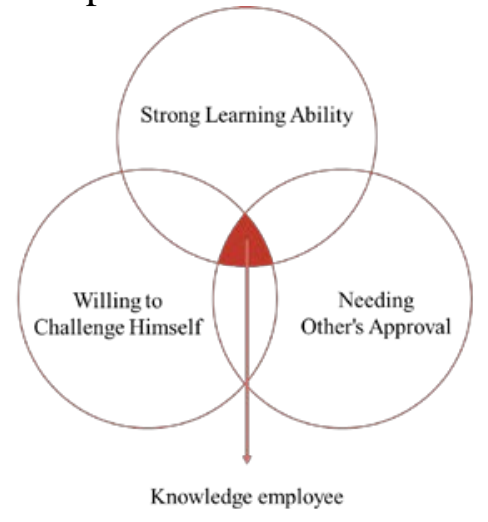

Figure 1. Characteristics of knowledge employee

\section{Summary of Management Psychology}

Management psychology is an important part of modern management theory. It starts from management, studies people's psychological activities with knowledge of psychology, management, sociology and so on. In the complex and complex management process, the management of the indefinite law. People, as the intelligent part of the universe is complex and full of feelings, understanding, different personality, ability and their needs and motivation, suitable for the human nature management, take effective measures to enable employees to maintain a positive attitude, which can inspire the enthusiasm of their work. In fact, management is to integrate the limited resources of the organization, seize the most important resource of human beings. When configuring other resources, managers can achieve the desired results if the procedures are reasonable and the conditions are enough. As a discipline that studies the rule and mechanism of individual's psychological activity, psychology has unique characteristics for the research of human resource development and management, especially the concern for individuals. First, psychology chooses or understands problems from the micro level, and is concerned about specific problems related to people in every aspect of enterprise management. Second, psychology is the human centered thinking and solving of human resources problems. It has a tolerant attitude towards individual weaknesses, shortcomings and shortcomings, and has great humanized care characteristics. Therefore, in the implementation of scientific management, we must attach importance to and apply the theories and methods of management psychology, strengthen the management and research of human beings, fully tap the potential of employees to achieve organizational goals and improve work efficiency.

\section{Efficient Incentive Methods of Knowledge Employee from the Perspective of Management Psychology}

\subsection{Offer Rapid Growth Opportunities}

It is very important for a knowledge-based employee whether the organization has a good habit of training employees and a training system. In the training process, pay attention to guiding the 
knowledge staff to achieve their personal goals and organizational value of its own collective goal together, so that knowledge workers to establish a correct outlook on life, moral concepts and values, establish organizational goals, the historical sense of responsibility and mission, to provide a good basis for knowledge innovation enthusiasm their enterprising spirit at work and play. The organization should also combine the characteristics of the staff, and give the opportunity to study abroad for further study, job promotion, professional technology research and so on. This is an important way to improve the knowledge and technology renewal ability of knowledge workers, promote the improvement of their own quality and realize the great development of the organization. Enterprises should provide training and learning opportunities for the system. Enterprises should strengthen the training of knowledge workers to meet the development needs of knowledge workers. On the one hand, it reduces the possibility of knowledge workers' turnover, on the other hand, it also enhances knowledge workers' recognition of enterprises and plays an incentive role for them. Enterprises should provide opportunities and support for knowledge-based employees. It is necessary to fully understand the personal needs and characteristics of the knowledge-based staff and to guide and help their career. Only when the needs of the growth and development of the staff are constantly realized, the satisfaction will be enhanced.

\subsection{Construct Competitive Salary System}

Because of the different stages of social development, China's knowledge-based employees pay more attention to material incentives than foreign countries, and regard it as the most important incentive factor. Knowledge workers have many sources of information sources, and their consumption concept and desire are stronger. Therefore, it is particularly sensitive to the gap between the salary level and the outside world and the pursuit of fairness. And in the state of mind more found is dissatisfied, and the satisfaction of the place is often considered to be taken for granted. It is difficult to maintain its stability without the remuneration level and fairness of the external competitiveness. Modern enterprises need to update their salary grade and reward. China is now the knowledge staff's salary level too much, cannot on personal knowledge of the correct guidance, frequent adjustment of salary levels to increase the amount of administrative work, and the staff to achieve the purpose of excessive pursuit of the promotion, do not pay enough attention to the creation of innovation. Thus, the performance is stagnant. The structure of the remuneration is too single, without a certain flexibility, a series of incentives should be formulated to reward innovation. Make your own innovation due pay. Knowledge workers will be willing to create, keep up with the pace of the times, after all, these knowledgeable people are the first hand of the new era of information. They are in the forefront of the times, leading the progress of the new era. Salary rewards are the most important factors that affect the motivation of knowledge workers. Therefore, we should improve the incentive mechanism of knowledge workers. At the same time, enterprises make welfare strategies in accordance with their operational strategies, so that the welfare strategy can improve the performance of employees. The second is to form an innovative flexible welfare management measure to keep the company attractive for a long time. In addition, it is necessary to form a virtuous circle of knowledge workers with high welfare and high performance to absorb more talents.

\subsection{Implement Reasonable Work Authorization}

As the pursuit of knowledge workers for autonomy and respect and recognition of others is strong, the organization's management should be based on the characteristics of knowledge workers, by authorization, let knowledge employees participate in the management of employees, granted some autonomy and decision rights, allowing it to work independently and take more responsibility. Authorization is to let employees enjoy the right to speak in the work, the decision right even the liberalization, empower and let them work independently. Let the staff authorized decision-making ability and experience accumulation, and from experience to successfully navigate the challenges, pleasure and sense of achievement. In this way, employees' inner motivation can be excavated, and knowledge workers can be involved in management, so that they will be willing to undertake organizational risk as an operator and reduce the cost of knowledge transformation. Flexible working is reduced due to the monotonicity of the time and the place of work is fretful sense, weakening the 
knowledge staff felt from the management of the shackles, which can motivate the work of the. The establishment of an innovative empowerment mechanism represented by self-management team. The basic features of this organizational structure are that the work team makes most of the decisions, the team leaders are the leaders, not the bosses. Information communication is carried out directly between people and there is no intermediate link. The team will determine and undertake the corresponding responsibility independently. Identify and implement the work plan by the team. Authorization has reduced the interdependence within the organization to a minimum, changing the past management, monitoring, instruction, command and other rigid management forms. Reasonable authorization has enhanced the immense autonomy of knowledge workers and stimulated the enthusiasm of knowledge workers.

\subsection{Establish Harmonious Culture Atmosphere}

To build an open learning organization to improve the adaptability of the enterprise to social change. Within the enterprise, the internal communication flow should be expanded through team building, and the team construction should be used to guide the employees to integrate into the collective and enhance the sense of belonging. This team building can be carried out either through the formal organization within the enterprise or through the informal learning group or the unfixed project team. It is a way of organizing employees to organize and represent their social environment. Learning organization advocates and emphasizes that everyone in the organization learn from each other for a long time, so that wider new thinking mode and new knowledge can be introduced continuously, and become a part of organization. Through learning, we can promote organizational change, increase membership ability and create real performance of organization. Knowledge workers pay more attention to personal growth, and pay more attention to the opportunity of continuous learning provided by the organization. The most successful enterprise in the future will be the learning organization. Through the establishment of a learning organization, effective investment in human capital, so that each member's knowledge can be constantly updated and enriched, and constantly improve their skills. Only when employees can clearly see their organizations in the future, which is the driving force for the organization dedicated to contribute their efforts to form a long-term cooperation the partnership with the organization and sharing weal and woe. Therefore, managers should create a harmonious interpersonal relationship atmosphere, resolve conflicts in time, adjust contradictions, and advocate two-way communication between upper and lower levels and communication between peers. The enterprise can stimulate the enthusiasm and innovation ability of knowledge workers to a greater degree.

\section{Conclusions}

Any incentive means must start from the characteristics of the knowledge workers themselves. Managers should study their needs, grasp their psychological characteristics, carefully design the organizational environment conducive to the development of knowledge workers. The knowledge employee motivation model based on management psychology can make the knowledge employees play their boundless potential. As the enterprises grow together, the interests of the employees and the interests of the enterprises can be achieved.

\section{References}

[1] Lu Yumei, Gao Peng, Gao Jie, et al. Research on Incentive Mechanism of the Knowledge Employee Responsibility [J]. On Economic Problems, 2016(1): 100-107.

[2] Bai Guiyu, Xu Xiangyi, Xu Peng. The Relationship Between Non-material Incentive of Knowledge Workers and Innovation Performance [J]. Research on Economics and Management, 2016, 37(5): 121-128.

[3] Liu Xiangyang, Li Fan. Study on Incentive Mechanism of Knowledge Workers based on Psychological Contract [J]. Technoeconomics \& Management Research, 2013(11): 51-56. 
[4] Xu Guang, Zhong Jie, Gao Yang. Study on the motivation of the knowledge staff innovation behavior-based on the perspective of psychological contract [J]. Scientific Management Research, 2016, 34(4): 89-92. 